\title{
PENERAPAN MODEL INKUIRI SOSIAL UNTUK MENINGKATKAN KEMAMPUAN BERPIKIR KRITIS MAHASISWA CALON GURU SD
}

\author{
Deasy Rahmawati ${ }^{1}$, Ike Annita ${ }^{2}$ \\ 1, 2PGSD FKIP Universitas Langlangbuana \\ 1deasyrahmawati35@gmail.com, 2rosadianita2016@gmail.com
}

\begin{abstract}
This aims of this study is to comprehendthin increase in the critical thinking skills of PGSD students through the implementation of social inquiry models in elementary social studies education courses. The population of this study were all 3rd semester students of the PGSD FKIP Unla study program. Sampling was carried out by using saturated sampling technique, where all members of the population were sampled, class A01 as a control class that applied conventional learning and class AO2 as an experimental class that was treated with social inquiry learning models. The data in this study were obtained through the results of the pretest and posttest using the critical thinking essay test instrument. The results of this study indicate that there are differences in the increase in the critical thinking skills of PGSD students in the SD social studies course after the social inquiry learning model is applied. Beside that, the critical thinking skills of PGSD students in the Elementary Social Sciences Education course after applying the social inquiry learning model are better than the control class using conventional learning methods.
\end{abstract}

Keywords: Social Inquiry Model, Critical Thinking Ability

\begin{abstract}
ABSTRAK
Penelitian ini bertujuan untuk mengetahui peningkatan kemampuan berpikir kritis mahasiswa PGSD melalui penerapan model inkuiri sosial dalam mata kuliah pendidikan IPS SD. Populasi dalam penelitian ini adalah seluruh mahasiswa semester 3 program studi PGSD FKIP Unla. Penarikan sampel dilakukan dengan teknik sampling jenuh, dimana seluruh anggota populasi dijadikan sampel, yaitu kelas A01 dijadikan kelas kontrol yang menerapkan pembelajaran konvensional dan kelas A02 dijadikan kelas eksperimen yang mendapatkan perlakuan model pembelajaran inkuiri sosial. Data yang dalam penelitian ini diperoleh melalui hasil pretes dan postes dengan menggunakan instrumen tes uraian berpikir kritis. Hasil penelitian ini menunjukkan bahwa terdapat perbedaan peningkatan kemampuan berpikir kritis mahasiswa PGSD pada mata kuliah Pendidikan IPS SD setelah diterapkan model pembelajaran inkuiri sosial. Selain itu, kemampuan berpikir kritis mahasiswa PGSD pada mata kuliah Pendidikan IPS SD setelah diterapkan
\end{abstract}


model pembelajaran inkuiri sosial lebih baik daripada kelas kontrol yang menggunakan metode pembelajaran konvensional.

Kata Kunci: Model Inkuiri Sosial, Kemampuan Berpikir Kritis

\section{A. Pendahuluan}

Memasuki abad ke-21 ada empat kecenderungan perubahan yang akan mempengaruhi pola-pola kehidupan yaitu pertama, perubahan lingkungan ekonomi, sosial dan pengetahuan dan teknologi; kedua, perubahan dalam lingkungan kerja; ketiga, perubahan dalam harapan pelanggan; dan empat, perubahan harapan para pekerja. Dengan demikian, pada tatanan global ini seluruh umat manusia di dunia dihadapkan pada tantangan yang bersumber dari perkembangan global sebagai akibat pesatnya perkembangan ilmu pengetahuan dan teknologi. Perkembangan ini harus diiringi dengan peningkatan kualitas sumber daya manusia yang mampu menjadi pengguna dan pengendali semua perkembangan ini.

\begin{tabular}{ccc}
\multicolumn{1}{c}{ Bangsa } & yang & mampu \\
membenahi & dirinya & dengan \\
meningkatkan & Sumber & Daya
\end{tabular}
Manusia-nya, kemungkinan besar akan mampu bersaing dalam kompetisi sehat tersebut. Disinilah lembaga tinggi pendidikan harus menampilkan dirinya, untuk mendidik dan menghasilkan para lulusan yang berdaya saing tinggi (qualified). Perguruan Tinggi merupakan lembaga yang sangat diharapkan perannya dalam menghasilkan sumberdaya manusia yang berkualitas. Dihadapkan pada era persaingan bebas, calon pendidik profesional terutama calon pendidik sekolah dasar dituntut untuk siap menghadapi era globalisasi ini.

Diberlakukannya kurikulum 2013 di Indonesia, menuntut guru untuk melaksanakan pembelajaran yang melatih kemampuan berpikir tingkat tinggi (higher order thinking skil//HOTS). Hasil pengamatan yang dilakukan peneliti, menunjukkan bahwa inisiatif dan kemampuan berpikir tingkat tinggi mahasiswa PGSD khususnya pada mata kuliah Pendidikan IPS sangat kurang, hal ini ditunjukkan dengan hasil tugas-tugas yang diberikan kurang memenuhi standar nilai yang telah ditetapkan. Kemampuan analisis yang sangat kurang ditemukan dalam jawaban UTS dan UAS yang belum memenuhi 
standar penilaian. Hal ini menjadi suatu hal yang harus ditindaklanjuti, karena akan berpengaruh pada rendahnya kompetensi lulusan PGSD ketika terjun langsung di sekolah. Dibutuhkan sebuah pembiasaan dan pembelajaran di kampus yang mampu mengasah keterampilan berpikir mahasiswa agar mampu menguasai materi perkuliahan, berpikir reflektif, peka terhadap berbagai perubahan, dan mampu menyajikan pembelajaran yang baik, bermakna sesuai dengan kaidah standar pembelajaran yang ditetapkan di dalam kurikulum 2013.

Richard, (1997) dalam penelitiannya terhadap sejumlah guru menyebutkan dari sejumlah responden, hanya 19\% guru yang dapat menjelaskan konsep berpikir kritis dengan jelas, dan hanya $9 \%$ dari responden tersebut yang melaksanakan proses pembelajaran yang dapat meningkatkan keterampilan berpikir kritis. Pentingnya kemampuan berpikir tingkat tinggi pada diri seorang guru agar dapat menghadirkan pembelajaran yang HOTS di kelas.

Fakultas Keguruan dan IImu Pendidikan Program Studi Guru Sekolah Dasar (PGSD) sebagai
Institusi pencetak calon pendidik di sekolah dasar bertanggungjawab untuk melahirkan para pendidik yang profesional yang memiliki keterampilan dalam menyajikan pembelajaran yang aktif, kreatif, efektif, menyenangkan dan berpusat pada peserta didik. Melalui kegiatan perkuliahan yang membiasakan mahasiswa bernalar atau berpikir kritis, diharapkan tercipta suasana belajar yang memberikan suatu perubahan tingkah laku yang baru secara keseluruhan sebagai hasil dari pengalamannnya sendiri dalam interaksi dengan lingkungannnya (Slameto, 2010).

Salah satu kompetensi yang harus dibangun oleh lulusan PGSD adalah kompetensi pedagogik yang harus mampu menyampaikan berbagai mata pelajaran, salah satunya IPS. Berkaitan dengan hal ini lulusan PGSD harus mampu merancang pembelajaran IPS yang menarik dan bermakna, sehingga pembelajaran IPS tidak hanya sebatas menambah pengetahuan (fakta, konsep dan generalisasi) saja tetapi dapat membantu para siswa untuk mengembangkan sikap, nilai dan keterampilan membuat keputusan-keputusan yang bersifat 
reflektif sehingga mereka dapat memecahkan masalah-masalah pribadi dan membentuk kebijakan umum dengan cara berpartisipasi dalam kegiatan sosial (Sapriya, 2016).

\section{Berpikir Kritis}

Dewey mendefinisikan berpikir kritis sebagai sebuah proses "aktif"dan mendefinisikannya sebagai pertimbangan aktif, dan hati-hati terhadap keyakinan atau bentuk pengetahuan yang seharusnya dengan alasan yang mendukung dan kesimpulan lebih lanjut yang mengarah padanya. Definisi tersebut selaras dengan pendapat Ennis (1996, hlm. 48) bahwa, berpikir kritis merupakan cara berpikir reflektif yang masuk akal atau berdasarkan nalar untuk menentukan apa yang akan dikerjakan dan diyakini. Definisi lain yang selaras dikemukakan oleh Iskandar (2009, hlm. 86-87) : Kemampuan berpikir kritis merupakan kegiatan panalaran yang reflektif, kritis, dan kreatif, yang berorientasi pada suatu proses intelektual yang melibatkan pembentukan konsep (conceptualizing), aplikasi, analisis, menilai informasi yang terkumpul (sintesis) atau dihasilkan melalui pengamatan, pengalaman, refleksi, komunikasi sebagai landasan kepada suatu keyakinan (kepercayaan) dan tindakan.

Beyer (dalam Sapriya, 2016, hlm. 146) menegaskan bahwa ada seperangkat keterampilan berpikir kritis yang dapat digunakan dalam studi sosial atau untuk pembelajaran disiplin ilmu-ilmu sosial, keterampilan tersebut, 1) Membedakan antara fakta dan nilai dari suatu pendapat; 2) Menentukan realibilitas sumber; 3) Menentukan akurasi fakta dari suatu pernyataan; 4) Membedakan informasi yang relevan dari yang tidak relevan; 5) Mendeteksi penyimpangan; 6) Mengidentifikasi asumsi yang tidak dinyatakan; 7) Mengidentifikasi tuntutan dan argument yang tidak jelas atau samar-samar; 8) Mengakui perbuatan yang keliru dan tidak konsisten; 9) Membedakan antara pendapat yang tidak dan dapat dipertanggungjawabkan; 10) Menentukan kekuatan argumen.

Trianto (2007: 116) menyatakan bahwa pembelajaran inkuiri merupakan rangkaian kegiatan yang menekankan pada proses berfikir secara kritis, analisis, dan dialeksis untuk mencari dan menemukan 
sendiri jawaban dari suatu masalah yang dipertanyakan. Banks (dalam Sapriya, 2016), menyatakan bahwa tujuan dasar dari inkuiri sosial adalah untuk menghasilkan pengetahuan dalam bentuk fakta, konsep, generalisasi dan teori. Model pembelajaran inkuiri sosial berorientasi pada interaksi sosial antar individu. Menurut teori ini pendidikan dapat mengembangkan individu secara individual dengan merefleksikan cara-cara menangani berbagai informasi dalam konsep dan nilai-nilai.

Kemampuan berpikir kritis tiap mahasiswa berbeda-beda, tetapi setiap mahasiswa pada akhirnya harus memiliki kompetensi tersebut supaya mampu menerapkan pembelajaran yang sesuai dengan kaidah kurikulum yang berlaku. Berdasarkan latar belakang di atas, peneliti tertarik untuk meneliti "Penerapan Model Inkuiri Sosial Untuk Meningkatkan Kemampuan Berpikir Kritis Dan Keterampilan Sosial Mahasiswa calon pendidik sekolah dasar".

Rumusan masalah dalam penelitian ini adalah. 1) Apakah kemampuan berpikir kritis mahasiswa kelas eksperimen yang menerapkan model pembelajaran inkuiri sosial lebih baik daripada kelas kontrol yang menggunakan metode pembelajaran konvensional?; 2) Apakah terdapat perbedaan peningkatkan kemampuan berpikir kritis mahasiswa setelah diterapkan model pembelajaran inkuiri sosial model pembelajaran inkuiri sosial?

\section{B. Metode Penelitian}

Penelitian ini merupakan penelitian eksperimen semu (kuasi eksperimen). Metode penelitian kuasi eksperimen menurut Sukmadinata (2011), pada dasarnya sama dengan penelitian eksperimen murni, yang membedakannya adalah dalam pengontrolan variabel. Pengontrolan variabelnya hanya dilakukan terhadap satu variabel saja, yaitu peningkatan kemampuan berpikir kritis dan keterampilan sosial. Sebagaimana yang diungkapkan oleh Sugiyono (2008:79) "penelitian eksperimen kuasi merupakan penelitian yang dimaksudkan untuk mengetahui ada tidaknya akibat dari "sesuatu" yang dikenakan pada peserta didik."

Desain penelitian yang digunakan yaitu Nonequivalen Control Group Design dengan 
Didaktik : Jurnal IImiah PGSD STKIP Subang,

kelompok eksperimen maupun kelompok kontrol tidak dipilih secara random. Kelompok Desain Nonequivalen Control Group Design dapat terlihat pada bagan di bawah ini.

\begin{tabular}{|ccc|}
\hline $\mathrm{O}_{1}$ & $\mathrm{X}$ & $\mathrm{O}_{2}$ \\
\hline & & $\mathrm{O}_{2}$ \\
\hline
\end{tabular}

Gambar 1

Desain Penelitian (Sugiyono,2013:79)

Keterangan :

X : Perlakuan Model Pembelajaran Inkuiri Sosial

$\mathrm{O}_{1}$ : Pretest kelas eksperimen dan kelas kontrol

$\mathrm{O}_{2}$ : Postest kelas eksperimen dan kelas kontrol

Populasi penelitian ini sebanyak 60 orang, yang terbagi ke dalam dua kelas yaitu kelas A01 dan A02. Sampel penelitian diambil dengan teknik sampling jenuh sampling jenuh, yaitu menggunakan seluruh anggota populasi menjadi sampel. Variabel yang diukur adalah kemampuan berpikir kritis mahasiswa PGSD pada mata kuliah Pendidikan IPS SD tahun akademik 2020-2021 setelah diberikan perlakuan model pembelajaran inkuiri sosial.

Teknik pengumpulan data berupa tes berbentuk soal uraian untuk mengukur kemampuan berpikir kritis. Tes uraian digunakan untuk mengetahui jawaban responden yang sifatnya terbuka dan dianalisis tingkat kemampuan berpikir kritis sampel yang diteliti. Analisis data dilakukan terhadap hasil tes (pretes dan posttes) yang dilakukan secara individual. Selanjutnya dilakukan pengolahan analisis statistik menggunakan software SPPS version 22.0 for Windows dalam beberapa tahap pengujian yaitu uji prasyarat (uji normalitas dan uji homogenitas), Uji-T (jika normalitas sampel dan homogenitas terpenuhi) atau Uji Mann Whitney (jika normalitas sampel dan homogenitas tidak terpenuhi) dan uji gain.

\section{Hasil Penelitian dan Pembahasan}

\section{Hasil Penelitian}

Hasil analisis data pretes, postes dan N-gain keterampilan berpikir kritis mahasiswa tersaji pada tabel berikut.

Tabel 1 Pretes, Postes dan N-Gain Kemampuan Berpikir Kritis Mahasiswa PGSD

\begin{tabular}{ccccccc}
\hline \multicolumn{6}{c}{ Kelas Eksperimen } \\
\hline $\mathrm{N}$ & \multicolumn{2}{c}{ Pretest } & \multicolumn{2}{c}{ Postest } & \multicolumn{2}{c}{ N-Gain } \\
\hline \multirow{2}{*}{30} & $\overline{\mathrm{x}}$ & $\mathrm{S}$ & $\overline{\mathrm{x}}$ & $\mathrm{s}$ & $\overline{\mathrm{x}}$ & $\mathrm{S}$ \\
\cline { 2 - 7 } & 59,1 & 10,4 & 76,9 & 7,8 & 0,51 & 0,24 \\
\hline
\end{tabular}

\begin{tabular}{ccccccc}
\hline \multicolumn{8}{c}{ Kelas Kontrol } \\
\hline $\mathrm{N}$ & \multicolumn{2}{c}{ Pretest } & \multicolumn{2}{c}{ Postest } & \multicolumn{2}{c}{$N$-Gain } \\
\hline \multirow{2}{*}{25} & $\overline{\mathrm{x}}$ & $\mathrm{S}$ & $\overline{\mathrm{x}}$ & $\mathrm{S}$ & $\overline{\mathrm{x}}$ & $\mathrm{S}$ \\
\cline { 2 - 7 } & 52,5 & 9,8 & 63,2 & 7,9 & 0,34 & 0,24 \\
\hline
\end{tabular}


Tabel 1, menunjukkan bahwa rata-rata pretes kelas eksperimen yang menerapkan model pembelajaran inkuiri sosial sebesar 59,1 dan kelas kontrol yang menerapkan pembelajaran konvensional sebesar 52,5. Selanjutnya rata-rata $\mathrm{N}$-gain pada kelas eksperimen adalah 0,51 dengan kategori peningkatan sedang. Sedangkan rata-rata $\mathrm{N}$-gain pada kelas kontrol adalah 0,34 dengan kategori peningkatan rendah. Hal ini menegaskan bahwa peningkatan keterampilan berpikir kritis di kelas eksperimen yang menggunakan model pembelajaran inkuiri sosial lebih tinggi dibandingkan dengan peningkatan keterampilan berpikir kritis kelas kontrol yang menerapkan pembelajaran konvensional.

Berdasarkan rumusan masalah pada penelitian ini, maka data yang dianalisis adalah selisih pretes dan postes (gain) dan N-gain. Data tersebut diuji normalitas, homogenitas dan uji perbedaan dua rata-rata. Taraf signifikansi yang digunakan yaitu $5 \%$ atau $\alpha=0,05$. Dari analisis data tersebut diperoleh hasil bahwa gain dan $\mathrm{N}$-gain tidak berdistribusi normal dan memiliki varians yang homogen, maka uji perbedaan dua rata-rata gain dan $\mathrm{N}$ gain keterampilan berpikir kritis mahasiswa PGSD dapat menggunakan uji non parametrik Mann Whitney. Uji Mann Whitney merupakan alternatif dari uji t, jika skala pengukuran lebih rendah dari skala interval dan asumsi distribusi normalitas sampel dan homogenitas tidak terpenuhi. Adapun kriteria pengujiannya adalah sebagai berikut:

a. Jika nilai sig (signifikansi) atau nilai probabilitas $>0.05$, maka $\mathrm{Ho}$ diterima.

b. Jika nilai sig (signifikansi) atau nilai probabilitas $<0.05$, maka $\mathrm{Ho}$ ditolak.

Hipotesis pertama ditentukan :

a. Ho diterima : tidak terdapat perbedaan kemampuan berpikir kritis mahasiswa PGSD pada mata kuliah Pendidikan IPS SD setelah diterapkan model pembelajaran inkuiri sosial.dengan kelas kontrol yang menggunakan metode pembelajaran konvensional.

b. Ho ditolak : kemampuan berpikir kritis mahasiswa PGSD pada mata kuliah Pendidikan IPS SD setelah diterapkan model pembelajaran inkuiri sosial. lebih baik daripada kelas kontrol yang menggunakan 
metode

pembelajaran

konvensional.

Berdasarkan hasil analisis data pembuktian uji hipotesis pertama tercantum dalam tabel berikut.

Tabel 2 Hasil Mann Whitney U Test Mann-Whitney Test

\begin{tabular}{|c|c|c|c|c|}
\hline & $\begin{array}{l}\text { Kelompok } \\
\text { kelas }\end{array}$ & $\mathrm{N}$ & $\begin{array}{l}\text { Mean } \\
\text { Rank } \\
\end{array}$ & $\begin{array}{l}\text { Sum of } \\
\text { Ranks }\end{array}$ \\
\hline \multirow{3}{*}{$\begin{array}{l}\text { Selisih_skor } \\
\text { berpikir kritis }\end{array}$} & Eksperimen & 30 & 37.88 & 1136.50 \\
\hline & Kontrol & 30 & 23.12 & 693.50 \\
\hline & Total & 60 & & \\
\hline
\end{tabular}

Test Statistics ${ }^{a}$

\begin{tabular}{|l|r|}
\hline & $\begin{array}{c}\text { Selisih_skor_be } \\
\text { rpikir_kritis }\end{array}$ \\
\hline Mann-Whitney U & 228.500 \\
Wilcoxon W & 693.500 \\
Z & -3.282 \\
Asymp. Sig. (2-tailed) & .001 \\
\hline
\end{tabular}

a. Grouping Variable: Kelompok_kelas

Tabel 2 menunjukkan mean rank atau rata-rata peringkat tiap kelompok yaitu pada kelas eksperimen rerata peringkatnya 37,88 lebih tinggi dari pada rerata peringkat kelas kontrol, yaitu 23,12. Nilai Mann-Whitney sebesar 228,5 dan nilai Wilcoxon sebesar 693,5. Apabila dikonversikan ke nilai Z maka sebesar -3,282. Adapun nilai signifikasinya sebesar $0,001<0,05$, maka $\mathrm{H}_{0}$ ditolak atau $\mathrm{H}_{1}$ diterima. Berdasarkan pembuktian tersebut, disimpulkan kemampuan berpikir kritis mahasiswa PGSD pada mata kuliah Pendidikan IPS SD setelah diterapkan model pembelajaran inkuiri sosial. lebih baik daripada kelas kontrol yang menggunakan metode pembelajaran konvensional. Hipotesis kedua ditentukan :

a. Ho diterima : tidak terdapat perbedaan peningkatan kemampuan berpikir kritis mahasiswa PGSD pada mata kuliah Pendidikan IPS SD setelah diterapkan model pembelajaran inkuiri sosial.

b. Ho ditolak : terdapat perbedaan peningkatan kemampuan berpikir kritis mahasiswa PGSD pada mata kuliah Pendidikan IPS SD setelah diterapkan model pembelajaran inkuiri sosial.

Berdasarkan hasil analisis data pembuktian uji hipotesis kedua tercantum dalam tabel 3 berikut.

Tabel 3 Hasil Mann Whitney U Test Mann-Whitney Test

\begin{tabular}{|l|l|r|r|r|}
\hline \multicolumn{1}{|c|}{ Ranks } \\
& Kelas & $\mathrm{N}$ & \multicolumn{1}{c|}{$\begin{array}{c}\text { Mean } \\
\text { Rank }\end{array}$} & $\begin{array}{c}\text { Sum of } \\
\text { Ranks }\end{array}$ \\
\hline Skor_ 1 & 30 & 36.73 & 1102.00 \\
ngain 2 & 30 & 24.27 & 728.00 \\
& Total & 60 & & \\
\hline
\end{tabular}




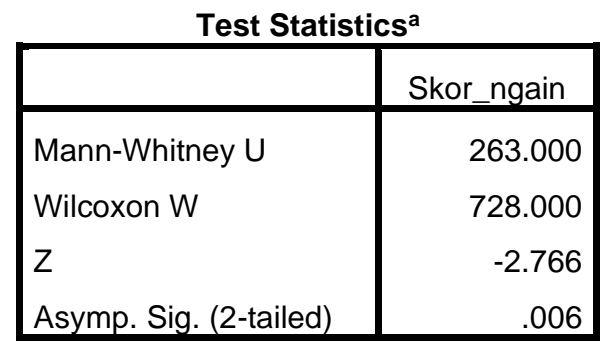

a. Grouping Variable: Kelas

Tabel 3 menunjukkan mean rank atau rata-rata peringkat tiap kelompok yaitu pada kelas eksperimen rerata peringkatnya 36,73 lebih tinggi dari pada rerata peringkat kelas kontrol, yaitu 24,27. Nilai Mann-Whitney sebesar 263 dan nilai Wilcoxon sebesar 728. Apabila dikonversikan ke nilai Z maka sebesar -2,766. Adapun nilai signifikasinya sebesar $0,006<0,05$, maka $\mathrm{H}_{0}$ ditolak atau $\mathrm{H}_{1}$ diterima. Berdasarkan pembuktian tersebut, disimpulkan terdapat perbedaan peningkatan kemampuan berpikir kritis mahasiswa PGSD pada mata kuliah Pendidikan IPS SD setelah diterapkan model pembelajaran inkuiri sosial.

\section{Pembahasan}

Evaluasi terhadap kemampuan berpikir kritis antara lain bertujuan untuk mendiagnosis tingkat kemampuan mahasiswa, memberi umpan balik keberanian berpikir mahasiswa, dan memberi motivasi agar mahasiswa mengembangkan kemampuan berpikir kritisnya. Dalam berpikir kritis dibutuhkan kemampuan bernalar secara sungguh-sungguh, sehingga memperoleh hasil pemikiran yang benar-benar diyakini berdasarkan pengetahuan yang dimiliki.

Tujuan umum penelitian ini adalah melihat penerapan model pembelajaran inkuiri sosial untuk meningkatkan kemampuan berpikir kritis mahasiswa PGSD pada mata kuliah Pendidikan IPS SD melalui model pembelajaran inkuiri sosial yang langkah-langkahnya pembelajarannya meliputi orientasi, merumuskan masalah, mengajukan hipotesis, mengumpulkan data, menguji hipotesis, dan merumuskan kesimpulan. Langkah orientasi, guru menjelaskan topik, tujuan, dan hasil belajar yang ingin dicapai, menjelaskan pokok-pokok kegiatan yang harus dilakukan, dan menjelaskan pentingnya topik dan kegiatan belajar. Langkah merumuskan masalah merupakan langkah membawa peserta didik pada suatu persoalan yang mengandung teka-teki untuk mencari jawaban yang tepat. Proses mencari 
jawaban itulah yang sangat penting dalam strategi inkuiri.

Kemudian untuk menjawab masalah yang telah dirumuskan, mahasiswa diberikan stimulus dengan pertanyaan-pertanyaan yang tertuang dalam lembar kerja mahasiswa pada langkah mengajukan hipotesis. Untuk menjawab pertanyaan-pertanyaan tersebut dan menguji hipotesis yang diajukan, mahasiswa secara berkelompok mengumpulkan datadata dari berbagai sumber. Mengumpulkan data adalah aktivitas menjaring informasi yang dibutuhkan untuk menguji hipotesis yang diajukan. Proses pengumpulan data bukan hanya memerlukan motivasi yang kuat dalam belajar, akan tetapi juga membutuhkan ketekunan dan kemampuan menggunakan potensi berpikirnya.

Langkah selanjutnya menguji hipotesis dengan cara mengkonfirmasi temuan dan teori yang ada. Terakhir, menyimpulkan permasalahan yang menjadi pokok bahasan yang tekah ditentukan.

\section{E. Kesimpulan}

Berdasarkan tujuan penelitian yang telah dibuktikan dengan hasil uji hipotesis dan hasil analisis data, maka dapat disimpulkan sebagai berikut.

1. Kemampuan berpikir kritis kelas eksperimen yang menerapkan model pembelajaran inkuiri sosial lebih baik daripada kelas kontrol yang menggunakan metode pembelajaran konvensional.

2. Terdapat perbedaan peningkatan kemampuan berpikir kritis kelas eksperimen yang menerapkan model pembelajaran inkuiri sosial setelah diterapkan model pembelajaran inkuiri sosial.

\section{DAFTAR PUSTAKA}

Bremer, C.D. \& Smith, J. (2004). Teaching Social Skills. National Center on Secondary Education and Transition Information Brief, 3 (5).

Bruce, Joyce; Weil, Marsha; Calhoun, Emily (2007). Models of Teaching edisi 6, Boston: Allyn and Bacon.

Ellaine. (2009). Contextual Teaching and Learning: Menjadikan Kegiatan Belajar Mengajar Mengasyikkan dan Bermakna. Bandung MLC.

Ennis, R. H. (1985). Logical Basic for Measuring Critical Thinking Skill. Education Leadership. Association for Supervision and Curriculum Development. 
Fisher, Alec. (2009). Berpikir Kritis: Sebuah Pengantar. Jakarta: Erlangga.

Inch, Warnick, Enders. (2006). Critical Thinking and Communication, Edisi 5. Waston : Pearson.

Ishak. (2011). Penggunaan Model Pembelajaran Koopertif Tipe Jigsaw dalam Pembelajaran IPS untuk Meningkatkan Pemahaman Konsep dan Keterampilan Berpikir Kritis Siswa Sekolah Dasar. Tesis SPS UPI Bandung: Tidak diterbitkan.

Iskandar, Johan. (2001). Manusia Budaya dan Lingkungan: Kajian Ekologi Manusia. Bandung: Humaniora Utama Press.

Johson, Elaine. 2002. Contextual Teaching \& Learning Menjadikan Kegiatan Belajar Mengajar Mengasyikan dan Bermakna. Bandung: MLC.

Lyznicki, J. M., Young, D. C., Riggs, J. A., Davis, R. M., \& Dickinson, B. D. (2001). Obesity: Assessment and management in primary care. American Family Physician, 63(11), 21852196.

Sanjaya, Wina. (2008). Strategi Pembelajaran Berorientasi Standar Proses Pendidikan. Jakarta: Kencana Prenada Media Group.

Sapriya. (2011). Teori dan Landasan Pendidikan Kewarganegaraan. Bandung: Alfabeta.

Sjamsuddin dan Maryani E. (2008). "Pengembangan Program Pembelajaran IPS untuk
Meningkatkan

Kompetensi

Keterampilan Sosial." Makasar: Makalah pada Seminar Nasional.

Sugiyono. (2008). Metode Penelitian Kombinasi (Mixed Methods). Bandung: Alfabeta.

Sukmadinata, N.S. (2012). Pendekatan Penelitian

Pendidikan. Bandung:

PT.Remaja Rosdakarya.

Trianto. (2009). Mendesain Model Pembelajaran Inofatif Progresif. Jakarta: Kencana Prenada Group.dst. 